\title{
St. Jude Stage I Childhood Non-Hodgkin Lymphoma AJCC v8
}

National Cancer Institute

\section{Source}

National Cancer Institute. St. Jude Stage I Childhood Non-Hodgkin Lymphoma A/CC v8. NCI Thesaurus. Code C141218.

Stage I: A single tumor (extranodal) or single anatomic area (nodal), with the exclusion of the mediastinum or abdomen. (from AJCC 8th Ed.) 